\title{
Twenty Years Online! A brief history of Palaeontologia Electronica
}

\author{
Julien Louys, Andrew Bush, James W. Hagadorn, Norman MacLeod, \\ R. Timothy Patterson, P. David Polly, and Jennifer Pattison Rumford
}

\begin{abstract}
This issue marks the $20^{\text {th }}$ anniversary of Palaeontologia Electronica (PE). From modest beginnings as a series of discussions on the PaleoNet listserver in 1996, it has become a well-recognised venue for publication and dissemination of research, techniques, and resources in palaeontology. The journal has many "firsts" to its credit, from the first species named on the internet, the first scientific journal with a plain-language abstract, and the first PDF "reprints" in palaeontology. Over 20 years PE also tried many new approaches that weren't subsequently adopted by the broader scientific community, such as audio abstracts and animated journal covers. This anniversary issue gives us an opportunity to look back at the beginnings of the journal, its initial aims and aspirations, and to chronicle its evolution. It is as much a reflection of the changing nature of PE as it is a reminder of the larger scale changes that have taken place in the world of palaeontology, the internet, and our community over the past two decades.
\end{abstract}

Julien Louys. School of Culture, History, and Languages, ANU College of Asia and the Pacific, The Australian National University, Canberra ACT 2601, Australia julien.louys@anu.edu.au

Andrew Bush. Department of Ecology and Evolutionary Biology and Center for Integrative Geosciences, University of Connecticut, 75 N. Eagleville Rd, Storrs, Connecticut 06269-3043 USA

andrew.bush@uconn.edu

James W. Hagadorn. Denver Museum of Nature and Science, 2001 Colorado Blvd., Denver, CO 80205

USA jwhagadorn@dmns.org

Norman MacLeod. The Natural History Museum, Cromwell Road, London, SW7 5BD, UK; Department of Earth Sciences, University College, London, Gower Street, London WC1E 6BT, UK; and Nanjing Institute of Geology \& Palaeontology, Chinese Academy of Sciences, 39 Beijing, Donglu, Nanjing, China N.MacLeod@nhm.ac.uk

R. Timothy Patterson. Department of Earth Sciences, Carleton University, 1125 Colonel By Drive, Ottawa, Ontario. K1S 5B6, CANADA TimPatterson@CUNET.CARLETON.CA

P. David Polly. Earth and Atmospheric Sciences, Indiana University, 1001 E. 10th Street, Bloomington, Indiana 47405-1405, USA pdpolly@indiana.edu

Jennifer Pattison Rumford. Palaeontologia Electronica, Texas USA jennifer.rumford@gmail.com

Keywords: Electronic publishing, history, palaeontology, open access, journal

Copyright: @ April 2017 Coquina Press. This is an open access article distributed under the terms of the Creative Commons Attribution License, which permits unrestricted use, distribution, and reproduction in any medium, provided the original author and source are credited.

creativecommons.org/licenses/by/4.0/

Louys, Julien, Bush, Andrew, Hagadorn, James W., MacLeod, Norman, Patterson, R. Timothy, Polly, P. David, and Rumford, Jennifer Pattison, 2017. Twenty Years Online! A brief history of Palaeontologia Electronica. Palaeontologia Electronica 20.1.1E: 1-13 palaeo-electronica.org/content/2017/1843-twenty-years-online 


\title{
In the Beginning...
}

\author{
Norman MacLeod \\ Co-Executive Editor (1998 - 2000), Executive Editor (2000 - 2002)
}

Palaeontologia Electronica started as most things in science do... with an argument; actually, several arguments. The earliest reference I can find in the PaleoNet archives to a discussion about electronic publications was started by John Alroy who, while reportedly amusing himself on a Sunday afternoon in 1995, plotted publication frequency data for technical reports on fossil mammals. These plots seemed to indicate that the rate of publication for this group exhibited a decade-long decline. This post led to a discussion of that result, whether it was real, whether this trend could be found in other palaeontological discipline publication records and the like. Toward the end of that virtual conversation I ventured the interpretation that what John was seeing might not be a falloff in interest in, or in the number of practitioners of, fossil mammal systematics, but rather a saturation effect based on the economics of publishing; specifically increases in the production costs of palaeontological journals causing journals to limit or decrease their page counts. In the context of that speculation I suggested that, "If publication budgets are a problem, perhaps (at least part of) the answer is for the societies to engage in (or sponsor) some type of on-line publication series." Granted, interest in electronic publication was on the rise generally in 1995. Nevertheless, for better or for worse, that simple suggestion appears, in hindsight, to have let the cat out of the bag with regard to a debate that eventually led to the creation of the journal whose 20th anniversary we celebrate with this issue.

After this original mention discussion threads devoted to online publication in palaeontology, in whole or in part, began appearing at regular intervals on PaleoNet. My own participation in those discussions culminated in a personal decision to use PaleoNet to explore how on-line publishing in palaeontology might work. That experiment was the PaleoNet Forum which, beginning with Doug Erwin's essay Quo vadis Paleontology?, resulted in the online publication of nine essays that were released in 1995 and 1996 on the PaleoNet Web site. (Note: these essays are still available on the PaleoNet web site: see "Online Publications" at http://paleonet.org/page4.) For me these articles demonstrated not only that an interesting and high-quality online palaeontological journal was possible, but (1) could have a much greater topical range than any extant palaeontological journal; (2) could reach a larger audience than any extant palaeontological journal; and (3) could be assembled by a very small group of editors and production staff using server space that could be donated by some of the larger palaeontological research organizations. Apparently, the same thought occurred to a number of others, many of whom were the authors of PaleoNet Forum articles.

Having demonstrated to my own satisfaction that an online paleontological journal was possible, and having my hands full with research and teaching responsibilities (not to mention the management of PaleoNet), my plan was to cheer on whoever was willing to take this leap into the publishing void. Then, just as yet another of those PaleoNet conversations on electronic publication in paleontology was winding down, I received an e-mail from Tim Patterson. Tim wanted to take the basic concept of the PaleoNet Forum articles and expand those into a full-blown electronic journal; and he wanted to do it in collaboration with myself and a small group of enthusiasts, some of whom were already discussing this possibility among themselves. I recall asking myself whether I really could take this responsibility on at the time. In hindsight I think it turned out to be one of my better decisions.

The group that came together to produce PE, aside from Tim and I, consisted of Stefan Bengtson, James (Whitey) Hagadorn, Mark Purnell, and Bill Riedel. Very quickly we were joined by Bill's Ocean Drilling Program colleague, Jennifer Pattison Rumford, who was engaged actively in creating electronic publications. It was this 
group that created PE's concept, organization, format, workflow, etc. Through 1996 and 1997 we discussed, argued, compromised, and collaborated our way to the release of PE's first issue in January 1998. That issue was quite modest compared to this 20th anniversary issue. That's how it should be. But the innovation, the care, the commitment and the community spirit that infuses PE are as evident today as they were back in 1996.

Tim and I served nominally as PE's co-executive editors for two years (19982000); I went on to serve another two years after Tim stepped down, the latter part in editorial collaboration with James. But in reality each issue was very much a group effort. We often struggled during those first years with the challenges all creators of new journals struggle with: finding people to submit manuscripts, working with reviewers and authors to make each article as good as it could be, solving the inevitable technical problems as those arose, etc. But the largest challenge we struggled with was learning how to create and then run an electronic journal. It's not the sort of thing you get trained for in graduate school. Moreover, most (sane) people only become involved with such an endeavour once, and so have only a limited and inevitably idiosyncratic experience. We all worked very hard giving birth to and then taking care of our electronic baby. But like all parents we also had fun and learned a lot along the way. Looking back on that time, I believe keeping it fun was the key in the end.

Palaeontologia Electronica isn't a commercial journal; there's no profit motive for anyone involved. Nor is it a society journal. Of course PE is sponsored by professional societies and that sponsorship was (and remains) critical to its success. But PE isn't the primary technical publication of any of its sponsors. Thus, its creators weren't motivated by societal affiliation. No doubt each person who has worked on PE has done so for their own reasons. No doubt those reasons are many and varied, just like those of our authors, manuscript reviewers, associate editors, Advisory Board members, translators, etc. But I like to think that what holds PE together - uniquely in my view, for I know of no other journal which is organized in a similar manner - is simply the group commitment to providing an outlet for the sort of palaeontology that breaks new ground, and that's adventurous and experimental (in all senses of that word). Most importantly, I believe PE, more so than any of its sister publications and competitors, provides real insight into what attracted all of us to devote our time and our professional lives to the odd, but compulsively intriguing subject of palaeontology in the first place. In other words, so far as I can see from the vantage point of having observed its development over the past two decades, PE has not only succeeded in publishing and promoting what is best in palaeontology topically and technically, it has succeeded in being the manifestation of what is best in palaeontology from a social and communitarian perspective. Long may it continue to do, and to be, so.

\section{You've Come a Long Way, Baby!}

\section{R. Timothy Patterson \\ Co-Executive Editor (1998 - 2000)}

In 2017 Palaeontologia Electronica celebrates its vicennial. This milestone provides an opportunity to look back and, like the fossil organisms celebrated in its pages, examine how PE has evolved and adapted to an ever-changing publishing environment. It all started as an offshoot of a wide-ranging discussion on the future of journal publishing on the nascent Paleonet listserver. Core themes of the discussion included the difficulties that researchers were having in getting their work published, the difficulties that society-sponsored journals were having in staying in the black due to high printing costs, and complaints about how the major for-profit publishing houses were 
beginning to monopolize scientific publishing and, in the process, generally bankrupting university library budgets with steadily increasing fees. Norm proposed that a possible way to relieve budgetary pressures might be for "the societies to engage in (or sponsor) some type of on-line publication series."

A group of enthusiasts (see above) took the discussion offline to explore in more detail just what the creation of a fully electronic paleontological journal would entail. On the recommendation of Bill Riedel we were quickly joined by Jennifer Pattison Rumford, who had already amassed considerable publishing expertise in her work with the development of an electronic publication platform for the Ocean Drilling Program. Through the coming months we engaged in a lively and constructive discussion on the form an online web journal might take and the potential for such a journal to transcend the limitations of traditional publications through the inclusion of myriad digital innovations (e.g., sound, animations, 3D renderings, unlimited number of color plates, etc.). This discussion progressed exclusively by email between participants spread throughout Australia, North America and western Europe. At that point I had never met any of the others in person. That this online discussion could take place in 1996 was a marvel in itself; something that would not have been possible even five years earlier when the majority of us hadn't even obtained our first email accounts!

From the perpetually online world of 2017 it is sometimes difficult to perceive the massive changes in communication technology that occurred during the 1990s. To refresh memories, and for those who were not even born then, let us recall the state of the internet as we began our electronic journal discussions. The very first public web site in the world had been launched at CERN only four years earlier on August 22, 1991 (http://info.cern.ch/). Although Internet usage was increasing exponentially, most web sites were static and browsers were clunky. In parallel to the discussions going on within our group I launched my own personal research website in January 1996. I had received a do-it-yourself hypertext markup language (html) book for Christmas 1995 and, by trial and error, managed to develop a primitive web site that went live at the beginning of semester 1996. I was taken with the promise of the web and buoyed by our electronic journal discussions, so I forced the students in my winter 1996 semester paleontology class to build paleontological-themed web sites instead of writing traditional term papers. The attraction of having students make virtual paleontological gallery displays in html was that they could be shared as an educational resource throughout the world to schools and the public, as opposed to languishing on a shelf in my office. I grouped the web projects together with an online portal and named it the Hooper Virtual Natural History Museum, after Professor Ken Hooper, whom I had replaced as departmental micropalaeontologist upon his retirement. This virtual museum went live in April 1996. To provide an indication of just how starved the world was for internet content, this innovation received a full page write up in the New York Times (Quain's Web Reviews, 1996) and was part of the Canadian Pavilion at the Internet World's Exposition of 1996 (a fossilized version is preserved at: http://park.org/ Canada/Museum/hvpmdoor.html). Such was the general state of the internet into which Palaeontologia Electronica was launched in 1998.

After considerable discussion, from how to ensure electronic content would survive in the long run to developing a style guide, we were ready to mock-up an example issue and did so with the help of Technical Editor, Jennifer. We simultaneously realized that maintaining a journal was going to be a daunting task. Accordingly, we were very pleased to have David Polly join the team at the beginning of 1997 in parallel with a general call for papers. David started off in the capacity of technical editor but quickly assumed a bigger leadership role, becoming an Executive Editor in 2003, a role that he would continue to fill through 2015. Volume 1 Issue 1 of PE was launched in January 1998 and was composed of two editorials, four research articles, a book review, and review of a scientific meeting that had occurred in September of the previous year. To coin a phrase, "we've come a long way baby"! 
At that point the biological and palaeontological communities, and particularly practicing taxonomists, were still suspicious of this new-fangled electronic publication mode, although our credibility was considerably enhanced by the sponsorship of six palaeontological societies, which partially underwrote some of the costs associated with publishing the journal. Although electronic journals don't have the high production costs of print-based online journals, there remain numerous expensive behind-thescenes costs that must be met. Without the support of these organizations PE would never have gotten off the ground. Younger researchers were quick to appreciate the flexibility and scope for innovation offered by electronic publishing, and the rate of submissions increased. Credibility was further enhanced in September 1997 with the publication of the Nature article Plugging into electronic journals (Porteous, 1997), which extolled the virtues and potential of electronic publishing, giving PE extended coverage. Palaeontologia Electronica also received some serendipitous PR from the serial librarian community with publication of its first issue because it was chosen as the 5000th electronic journal to be listed on the Internet listserver NewJour.

What made PE attractive from the outset was the absence of publication fees, amazingly fast review turn-around times, and open access (OA) to all articles. These features set PE apart from the pack both then and now, particularly OA, with granting agencies increasingly demanding that publications disseminated from research funds be published without paywalls. Although in 2017 virtually all journals are accessed digitally, articles are essentially pdf copies of printed pages, with very few offering inclusion of the range of digital media offered by PE, a further distinction that PE offered from its very beginning.

Palaeontologia Electronica has evolved through the years. For example, the Internet had limited bandwidth in the early days, and to ensure that users everywhere would be able to access material easily, mirror sites were established throughout the world, a laborious requirement that, thankfully, is no longer needed. When issues were being put together Jennifer and I would often exchange several emails a day and spend hours on the telephone, a process that has since been streamlined. We experimented on many fronts. For example, to provide access to a broader community, not all of whom spoke English, we offered multilingual translations in addition to plain language abstracts. To provide access to the visually impaired we provided audio abstracts.

The biggest challenges for PE in maintaining our ideal of being a pure Internet journal related to meeting publication requirements under the International Code of Zoological Nomenclature (ICZN) and International Code of Botanical Nomenclature (ICBN). Although not as 'sexy' as some areas of palaeontological research, the description of new fossil organisms is an important activity that most paleontologists engage in at some point in their career. For its first two years of operation PE was not able to publish any systematic palaeontology papers involving the description of new taxa because ICZN and ICBN restricted the coining of new taxonomic names to paperonly publications. A breakthrough occurred in 2000 , when changes made in the $4^{\text {th }}$ (1999) edition of the ICZN permitted electronic publication of names provided that they were archived in "durable, unalterable" formats that were deposited in several archives. So, PE began to publish CDs that were sent to university and national libraries throughout the world for inclusion in their collections. Palaeontologia Electronica had the honor of publishing the first officially recognized description of new species in electronic format: Eggerella matsunoi, Haplophragmoides hatai, and H. nishikizawensis (Scott et al. 2000). The publication of these new species set an important precedent for authors seeking to take advantage of the unique descriptive and illustrative tools available with web-based technologies. The ICBN was a tougher nut to crack, not permitting the electronic publication of new names until 2005. To comply with ICBN requirements PE switched from CDs to print copies of archives in January 2007. Printing was initially carried out by Yale University, and beginning in 2010 by lulu.com. In 2011 both the ICZN and ICBN amended their requirements permitting electronic 
description of new taxonomic names, although ICZN required that they were simultaneously registered with the ZooBank database. This permitted PE to stop printing archival copies, although a print-on-demand option of PE issues is still available through lulu.com. To ensure that PE content remain available in perpetuity, agreements were signed in 2013 with CLOCKSS (a joint venture between the world's leading academic publishers and research libraries) to archive back issues permanently.

The old guard at PE has been largely supplanted by a new generation of early to mid-career editorial board members (see: http://palaeo-electronica.org/content/editors). These next-generation researchers grew up with the Internet and have a keen appreciation of the ongoing potential for $\mathrm{PE}$ to be at the leading edge of electronic publishing. However, a constant for the entire history of PE has been the presence of Technical/Managing Editor Jennifer Pattison Rumford who has worked tirelessly with authors and editors throughout the entire 20-year history of the journal to produce scholarly publications of the highest caliber.

In 2017 her Majesty Queen Elizabeth II marks her 65th or Blue Sapphire Jubilee. At 20 Palaeontologia Electronica has a long way to go to get to that milestone. That said, PE has established itself as a leading paleontology journal with the demonstrated ability to adapt and innovate in an ever-changing cyberspace, characteristics that metaphorically align well with that of a different queen - the Red Queen of Lewis Carroll and evolutionary biology.

\title{
In Transit
}

\author{
P. David Polly \\ Technical Editor (1998 - 2003), Co-Executive Editor (2003 - 2011), \\ Executive Editor (2011 - 2015)
}

Starting a new journal is not easy. Or, more accurately, keeping a new journal going is not easy.

In many ways PE followed the "long-fuse" model of evolution, starting with an incendiary flash in 1996, followed by a steady but sometimes flickering burn, until it became a firmly established member of the paleontological publishing community. Palaeontologia Electronica was ground-breaking in being the first primarily electronic journal of palaeontology; indeed it was among the first peer-reviewed online academic journals in the world. Norman MacLeod and Tim Patterson have described its genesis, which turned out to be more revolutionary than any of us knew because electronic publishing was to become the norm (no pun intended).

In the beginning, however, a fully electronic journal presented an unexpected conundrum. Senior members of the field - those whose jobs and reputations were so well-established that they could afford to publish in an unorthodox journal - tended to be suspicious of electronic publishing because of the question of long-term availability of a web-based publication. Would new taxonomic descriptions still be available in 10, 20 , or 100 years? Would researchers be aware of papers published in an issue that would never sit on the library's new acquisition shelf? The more junior members of the field were more unequivocally optimistic about the electronic future, but these researchers - graduate students, post-docs, and junior faculty - were routinely evaluated by metrics such as journal impact factors. And PE had no formally indexed impact factor because it was electronic.

In those days, both senior and junior researchers therefore tended to submit their work elsewhere. Once the first years of novelty wore off, it was not always easy to fill an issue because submission rates were so low. One only has to count the number of papers in each issue to see the pattern: we published only 4.2 papers per issue in vol- 
umes 4 (2001) through 9 (2006), except for the massive memorial issue to palaeontologist Will Downs, which had 28 papers in Volume 8.1. And we were only publishing two issues per year. We sometimes had to hold release of an issue until we had at least four papers in hand.

Our format was designed to be as much like print publication as possible in order to make authors feel comfortable. Once papers were accepted they were placed in the queue for the next issue, which were released twice per year. This format allowed us to announce each complete issue with a splash: on PaleoNet, on posters at GSA, Pal Ass, and SVP meetings, and, of course, on our homepage. However, releasing papers by the issue meant that we had to have enough papers not to look meagre, which meant that papers waited until issue publication to see the light of day. Ironically, in that part of PE's history, there was no such thing as an early online publication because our only publication was online.

2006 was a critical year. The Institute for Scientific Information (ISI) at Thompson Scientific (the predecessor of Thompson-Reuter's Web of Science and Journal Citation Reports) started indexing PE papers using their new rules for electronic journals. It was ISI that generated impact factors, which we badly needed to make junior authors comfortable with publishing in an increasingly metricized world. Impact factors were (and still are) the average number of citations per paper published by the journal within a two-year moving window. ISI released our first impact late in 2007; after that, PE's long fuse burst into a real explosion.

Remarkably, the editorial we wrote to announce our imminent impact factor (Riedel et al., 2006) made a splash in the journal metrics world. In it we argued that palaeontology journals had artificially low impact factors because only a fraction of citations were captured, due to ISI's peculiar rules for which ones to index. Monographs, which contain literally hundreds of citations, were not included because they were published periodically instead of by issue. We provided data for the large fraction of journals that were not included in impact factor calculations based on the Bibliography of Fossil Vertebrates index. Apparently our editorial was cited within citation metric circles (ironically all in grey literature, most of it online) as evidence that ISI's journal impact factors were flawed, prompting ISI's founder Eugene Garfield to write to me and James Hagadorn, "I believe there is some flawed logic in your arguments about coverage of this field unless there is evidence that, unlike all other fields I have studied, Bradford's Law of Scattering does not apply. In order to understand your field better if would help if I could see the list of 244 journals you mention as being listed in the Bibliography of Fossil Vertebrates." We sent them, he was satisfied, and he vowed to see that more paleontology journals were indexed.

Submissions were steady enough in 2007 to add a third issue each year, a key victory because it meant that papers were published no more than four months after they were accepted, and often within a week or two for the final paper in the issue. While that seems like a long delay from the perspective of 2017, it was extremely rapid publication in those days. For the next few years we averaged about 6 papers per year, and after 2010 the number started increasing steadily. The average number of papers quickly surpassed 15 per issue.

By that time, our issue-based publishing model was beginning to seem antiquated. The "early-online" format of print-based journals meant that it was, ironically, actually becoming slower to publish in PE. But our strong level of submission allowed us to completely abandon that format. In 2012, we moved to a continuous publication model in which new issues were opened three times a year with an empty table of contents, to which new papers were added within days after being accepted. Today PE has an extremely rapid time to publication after acceptance, as well as more papers per issue than the remarkable Will Downs issue. 
I want to close with one of PE's most remarkable but overlooked achievements: the Palaeontologia Electronica Manuscript Submission and Tracking System (PEMSATS). Palaeontologia Electronica was among the first journals to use an online manuscript handling system. As numbers of submissions grew we had a hard time tracking them without staff or piles and files of paper manuscripts. Palaeontologist Mark Sutton of Imperial College programmed PEMSATS himself, customized completely for PE. While PEMSATS is a bare-bones system in many ways, the fact that Mark provided it free of charge meant that we did not have to contract with a major publisher. This tremendous cost savings allows PE's three sponsoring societies - the Palaeontological Association, Paleontological Society, and the Society of Vertebrate Paleontology - to meet all of its costs with comparatively small financial contributions. Thanks to the combination of Mark's contribution of PEMSATS, Jennifer Pattison Rumford's dedication, the volunteer efforts of PE's editorial staff, and the financial input of the sponsoring societies, PE has (and always has had) a "green" open access format, with no charge to readers or to authors.

\title{
The Long View from Behind the Scenes
}

\author{
Jennifer Pattison Rumford \\ Managing Editor (1998 - present)
}

When we started this project it was like a dare. Jump off that roof top, climb that tree, make an online journal. It was exciting to be on the bleeding edge of a new technology.

I am not kidding that there were some articles that made me weep. And I have met so many extraordinarily nice people from all around the world, most of you only by email. I live in an old wooden house in a small old town in Texas and nearly every day something interesting rolls onto my screen from more countries than I can remember. That is, as long as I have electricity - because we do have power problems in my little old town.

There were some issues (because in the beginning we published an entire issue at a time instead of each article as it came finished), that I cursed and wept through, or gritted out due to technological issues, or took on vacation with me. One in particular was the Will Downs issue - http://palaeo-electronica.org/2005_1/index.html. My husband had made plans to go to a biker rally/music festival in Texas without consulting PE's publication schedule. There I was on a picnic table with my desktop computer plugged into the RV generator as bikers and their babes rolled through the campground, the women flashing for beads. A bearded biker dressed in leather from the campsite next to ours came over on the last day of the festival with a fistful of beads. We looked at each other over the top of my monitor, and he hastened to say he didn't want me to be the only woman without a neck full of beads and I didn't have to flash for them.

One thing that I remember from talking to other people in publishing - and PE made me a popular speaker for a few years in scientific publishing because no one else was doing what we were doing - is that science editors were shocked, disbelieving, and tickled to hear that palaeontologists were taking this leap. At that moment in the 1990s, in scientific publishing, palaeontologists had a reputation as being the most ivory of the ivory tower set. Going where no person had gone before was not something science editors expected from palaeontologists.

So it was really fun to prove them wrong. 
There are still so many interesting possibilities ahead of us - it remains one of the projects I always make time for. So when you're out in the field and you have that oncein-a-lifetime moment in your hands, don't forget that I am going to enjoy it just as much as you do, when PE's team of editors works to make it live across the Internet.

\title{
Twenty years of online palaeontology - publication trends 1997-2017
}

\author{
Julien Louys \\ Handling Editor (2012 - 2014), Executive Editor (2014 - 2016), \\ Co-Executive Editor (2017 - present)
}

As of the $3^{\text {rd }}$ March 2017, PE has published 489 research articles (with many more currently in production), 191 commentaries and reviews, as well as pushing the state-of-the-art in science dissemination with many online experiments in communication. Inevitably, some of these have fallen out of favour or have been superseded by developments in technology or software. For example, PE no longer provides audio abstracts, a result of numerous page voice readers available commercially or online, and often built into software itself. For many years PE hosted a section, "Our readers write to us", where we published emails from readers with feedback on how to improve our website. While we still accept feedback, perhaps as a result of the general acceptance of online academic publishing this feature has not been used since 2003. Palaeontologia Electronica has always accepted reviews of any material related to palaeontology. However, in the early years this included not only technical and popular books, but also videos and CD-ROMS, the latter falling by the wayside. On the other hand, PE has embraced new platforms, joining Facebook in 2010 with 76 'likes' (which has increased to 2510), a separate blog section in 2010, and Twitter in 2012. Our file management system has changed too, with the 2007 introduction of PEMSATS (see above), and a move to the Joomla platform in 2012, both of which have allowed us to better manage the increasing number of submissions and publications we have been receiving. In 20 years we have published five special issues: Paleontological databases: Taxonomic Decisions 'mini' issue (2.1); Will Downs memorial volume (8.1); the Morphometrics 'mini' issue (8.2); Three-Dimensional Imaging in Vertebrate Paleontology (11.2); and Charles A. Repenning memorial volume (14.3).

Initially, the numbers of submissions to PE were modest, with research articles largely supplemented by book and other reviews and commentaries (Figure 1). Notable exceptions in this trend, until recently, were the memorial volumes that saw marked spikes in the number of research articles published. (Although clearly by the $14^{\text {th }}$ volume overall publication trajectories were on their way up.) In recent years the numbers of submissions to PE have increased in an exponential fashion. We first noticed this spike about a decade ago. The rise was likely tied to a number of factors, not least the reputation the journal had achieved in the palaeontological community. However, indexing of the journal in the Science Citation Index in 2005, with its concomitant issuance of a Journal Impact Factor, as well as an overall global upward trend in the number of scientific papers published, also likely contributed to this trend. As a result, PE no longer struggles with submissions. In fact, one of our current challenges revolves around managing the huge number of submissions we receive and papers we publish. Some of this overload has been assuaged by an expanded editorial board, although much still falls on the shoulders of our fearless managing editor, Jennifer Pattison Rumford, who has borne this increase with unflappable enthusiasm and dedication. 


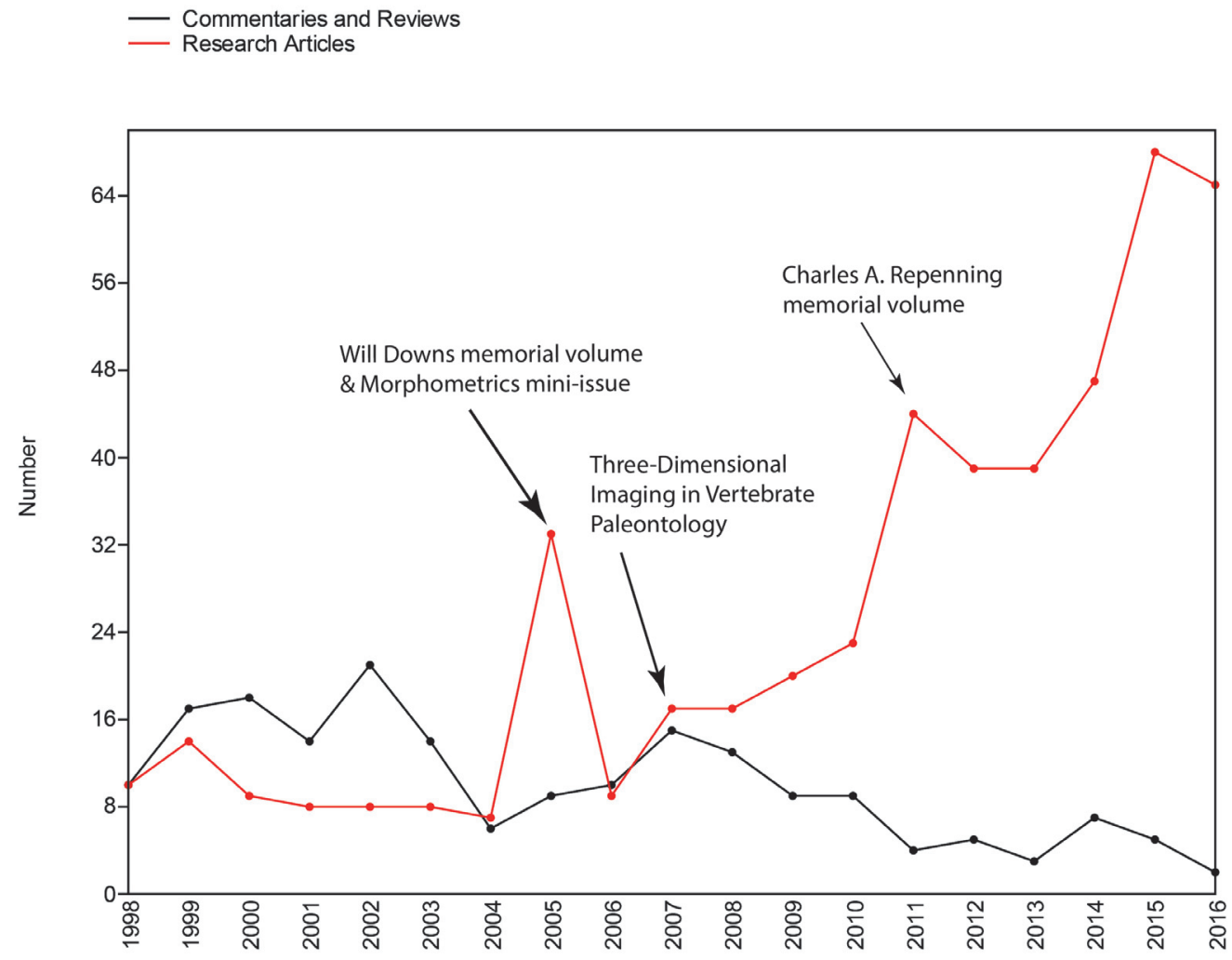

FIGURE 1. Numbers of published articles in Palaeontologia Electronica, per year (2017 exclusive). This graph was drawn using PAST ver. 2.17c (Hammer et al. 2001).

In an effort to delve deeper (dare I say unearth) PE's publishing trends over the last 20 years, I examined each research paper's publication category and the palaeontological sub-discipline it belongs to (Figures 2-3). There has been a noticeable increase in the number of research articles relative to review and technical articles, with the change happening sometime around 2010 or so (Figure 2). Although changes in the ICZN regulations regarding electronic publication occurred in 2000 , taxonomic publications did not see a proportional increase until around 2011. Publication in PE seems to have been enthusiastically taken up firstly by micro- and invertebrate palaeontologists, as their contributions dominate the first years of publishing (Figure 3). Following the Will Downs memorial volume and the Morphometrics mini-issue, vertebrate palaeontologists took to publishing in PE with gusto, such that papers dealing with this topic now make up a significant portion of submissions, and have done so over the last ten years or so. Perhaps the publication of the first memorial volume and subsequent vertebrate palaeontology themed special issues made vertebrate palaeontologists more aware and accepting of publishing in PE. Ichnology, stratigraphy/geology and palaeoecology papers have always had modest, but relatively continuous presence in our pages. Finally, it's interesting to note that certain disciplines have largely ignored PE as a publication venue, for example, palaeobotany until 2007, or the field of palynology from which we've very rarely published an article.

This snapshot of the last 20 years of publications allows us to address several of the initial hopes regarding the inception of the journal. One of the aims of an electronic journal was to provide a venue for a large topical range in palaeontology publishing. A quick look at Figure 3 or any given issue's table of contents provides positive confirmation that PE has and continues to fulfil this aspiration. Although I did not tabulate mono- 


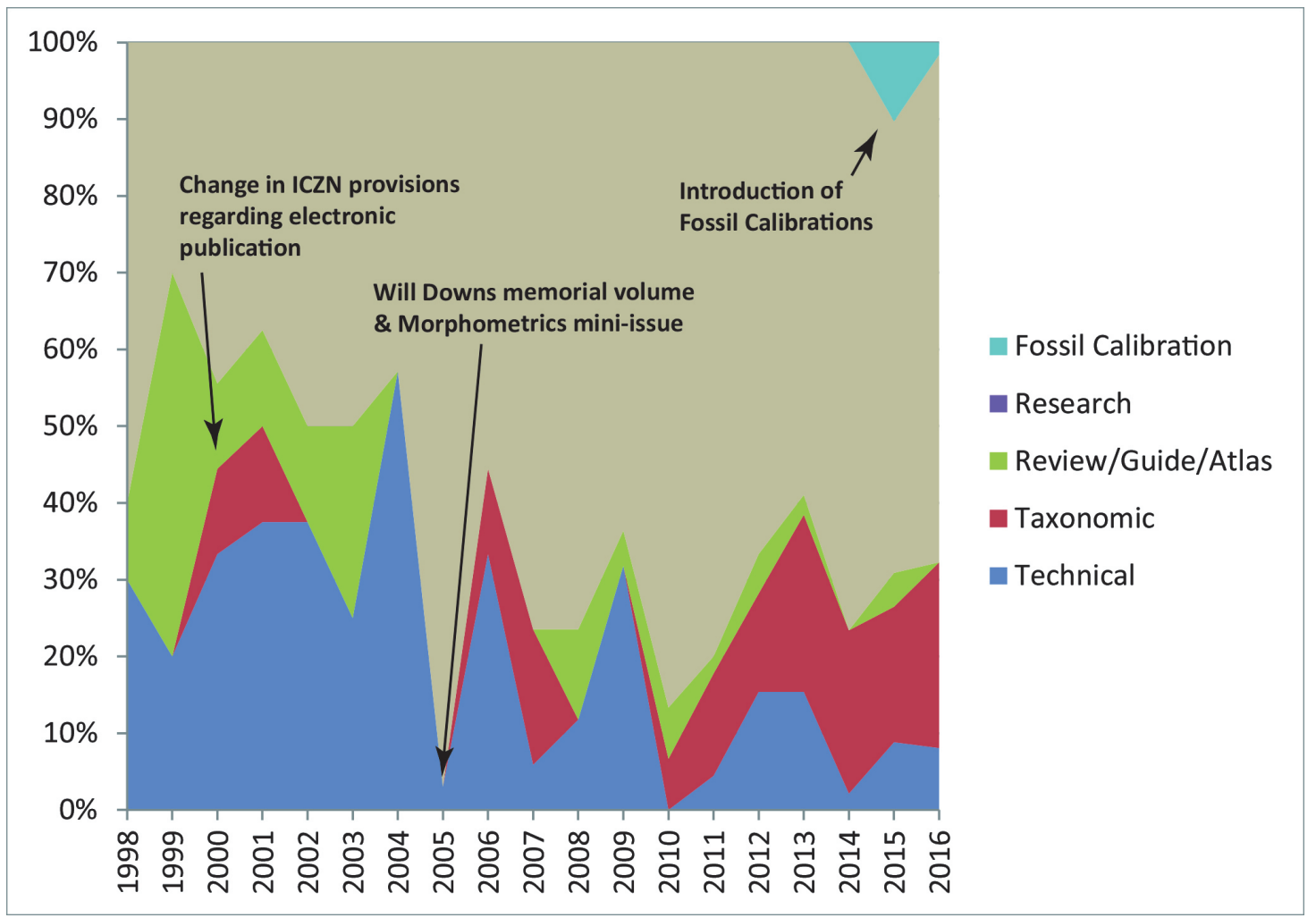

FIGURE 2. Research articles published in Palaeontologia Electronica for each year (2017 exclusive), expressed as a percentage of each article category. Over the years PE has published research articles in a number of sub-categories: a Critical Review category was used briefly, Technical Articles have been differentiated from Research Articles since 2009, and the Fossil Calibration Articles were introduced in 2015. However, for consistency and in order to examine our 20 year trends, I have gone back through all research articles and retroactively assigned each to one of five categories: Research, Technical, Taxonomic, Review/Atlas/Guide, and Fossil Calibration.

graphs separately, the publication of large treatises, atlases, taxonomic keys, etc. has allowed many of our authors to transcend the limitations of paper publications. Whereas most palaeontology journals now have an online presence, PE, perhaps more than any other, is still willing to experiment with publishing in different formats and is always happy to entertain different media or new ideas for the dissemination of palaeontological information. Finally, and I believe uniquely for scholarly publishing in palaeontology, the PE team has always employed a degree of humour and oftentimes tongue-in-cheek attitude, in part because it helps us infuse our principle subject matter- the dead- with life.

\section{The Future}

\section{Julien Louys and Andrew Bush Executive Editors}

Interestingly, the issues facing the larger palaeontological community 20 years ago are still the same today. Complaints about for-profit publication companies, author processing charges, and an increased awareness of the need for open access publications (see Louys, 2015) are still omnipresent. Palaeontologia Electronica fills a key niche in the world of scholarly palaeontological publications: established, stable, well- 


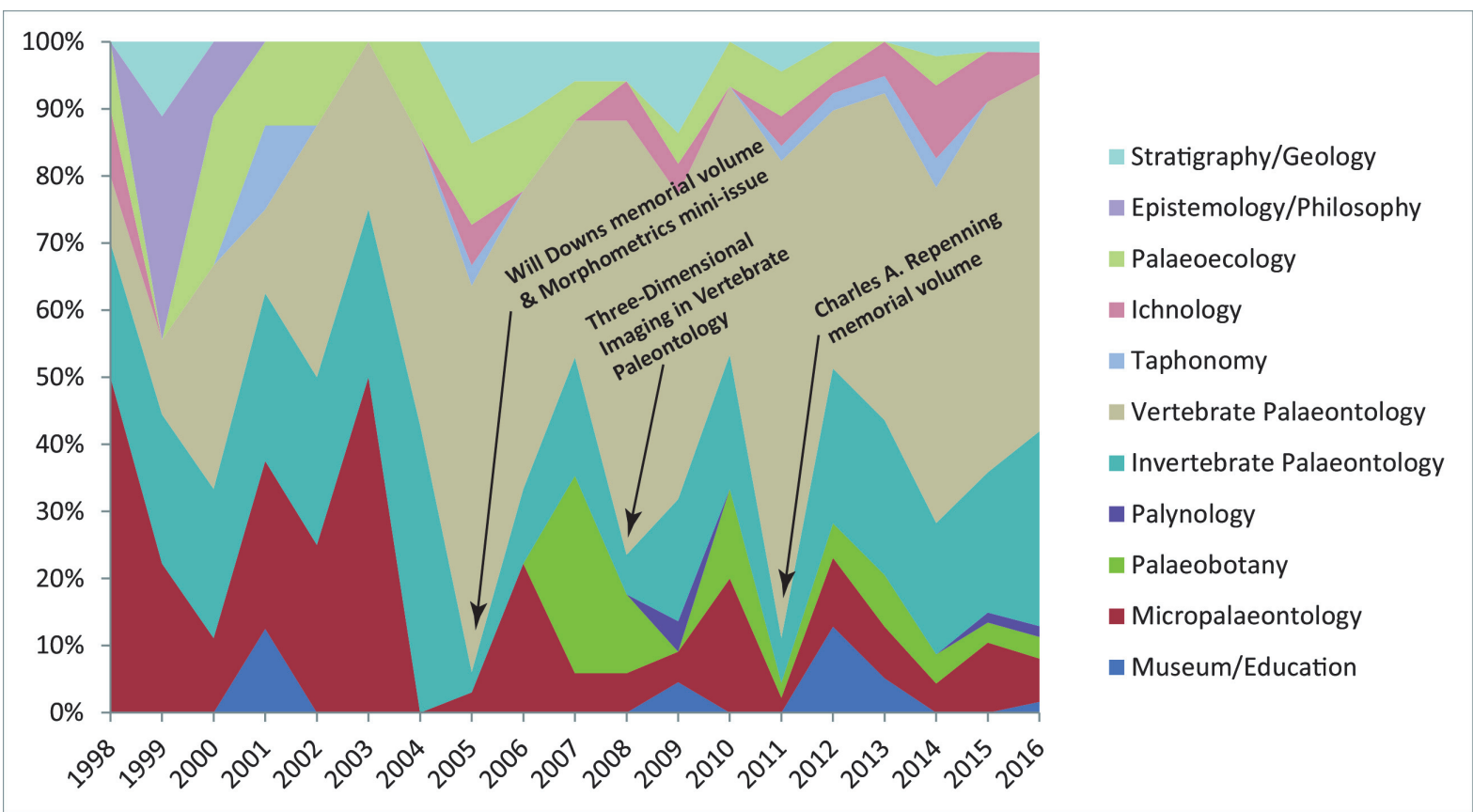

FIGURE 3. Research articles published in Palaeontologia Electronica for each year (2017 exclusive), expressed as a percentage of each palaeontological sub-discipline. This represents a somewhat more arbitrary (compared to Figure 2) assignment of each research article to one of 11 palaeontological sub-disciplines. This assignment is more arbitrary because many articles aren't easily categorised into a single sub-discipline and, depending on subject matter, the sub-disciplines themselves can overlap. Other articles, particularly highly technical articles, don't always fit so neatly within any strictly palaeontological sub-discipline. Nevertheless, primarily on the basis of article title, with reference to the abstract and keywords where necessary, each article has been assigned as Museum/Education, Micropalaeontology, Palaeobotany, Palynology, Invertebrate Palaeontology, Vertebrate Palaeontology, Taphonomy, Ichnology, Palaeoecology, Epistemology/Philosophy, and Stratigraphy/Geology.

regarded, and most importantly - freely available world-wide. This was our founding and remains our guiding principle. The journal has been and continues to be financially supported by our professional societies and intellectually supported by volunteers in the form of editors, translators, and peer-reviewers. The movement to a Creative Commons license for articles assigning copyright to the Society of Vertebrate Paleontology is another welcome development that we hope to see extended to all articles published with PE.

In a way, however, we are a victim of our own success, because our biggest challenge today is shepherding the large number of submissions to the journal. For example, we are actively working towards getting DOls for all our publications; however, such an endeavour costs money that we need to source. Staying at the vanguard of online publication is also a challenge, as numerous new and online publication models are proposed, some of which seek to move entirely beyond the traditional bounds of peer-reviewed journal articles. At 20 years, PE has achieved a degree of maturity and acceptance - it is now part of the establishment. The move to an online presence by most journals has seen a convergent evolution between what we publish and how we look, and what other palaeontology journals publish and how they look. What will the journal be like in 20 years? Time will tell, but it's our hope that some of the initial adventure and avant garde clearly present in PE's early days will remain alive and strong well into its future. 


\section{ACKNOWLEDGEMENTS}

Many thanks to all those who have been involved with PE over the years in any and all capacities, particularly past and present editors, peer-reviewers, translators, and authors, who have helped shape the journal into what it is today.

\section{REFERENCES}

Hammer, Ø., Harper, D.A.T., Ryan, P.D. 2001. Past: Paleontological Statistics Software Package for Education and Data Analysis. Palaeontologia Electronica, 4.1.4A: 1-9 http://palaeo-electronica.org/2001_1/ past/issue1_01.htm.

Louys, J. 2015. Palaeontologia Electronica in an increasingly open-access world. Palaeontologia Electronica 18.2.2E: 1-3 http://palaeo-electronica.org/content/ 2015/1259-commentary-open-access

Porteous, J. 1997. Plugging into electronic journals. Nature, 389 (6647): 137
Riedel, W.R., Polly, P.D. and Hagadorn, J.W. 2006. Coming of age: ISI and Googling. Palaeontologia Electronica, 9.1.1E: 1-3 http://palaeo-electronica.org/ paleo/toc9_1.htm

Scott, D. B., Takayanagi, Y., Hasegawa, S., and Saito, T. 2000. Illustration and taxonomic reevaluation of Neogene foraminifera described from Japan. Palaeontologia Electronica, 3.2.1A: 1-41 http://palaeoelectronica.org/2000_2/foram/issue2_00.htm 